\title{
Ingarden's combinatorial analysis of the realism-idealism controversy
}

\author{
Raphaël MiLLIÈRE \\ University of Oxford
}

The Controversy over the Existence of the World (henceforth Controversy) is without a doubt Ingarden's magnum opus; it is perhaps surprising, then, that so little attention has been given to its main goal, clearly indicated by the very title of the book: finding a solution to the centuries-old philosophical controversy about the ontological status of the external world. There are at least three reasons for this relative indifference. First, even at the time when the book was published, the Controversy was no longer seen as a serious polemical topic, whether it was disqualified as an archaic metaphysical pseudo-problem or taken to be the last remnant of an antiscientific approach to philosophy culminating in idealism and relativism. Second, Ingarden's reasoning on the matter is highly complex, at times misleading, and even occasionally faulty. Finally, his analysis is not only incomplete - Controversy being unachieved - but also arguably aporetic. One may wonder, then, why it is still worth excavating this mammoth treatise to study an issue apparently no longer relevant to contemporary philosophy. Aside from historical and exegetical purposes, which are of course very interesting in their own right, Ingarden's treatment of the Controversy remains one of the most detailed and ambitious ontological undertakings of the twentieth century. Not only does it lay out an incredibly detailed map of possible solutions to the Controversy, but it also tries to show why the latter is a genuine and fundamental problem that owes its hasty disqualification to various oversimplifications over the course of the history of philosophy. Whether Ingarden was right is a matter of personal judgment; but we can at least strive to do justice to his work by restituting his main arguments as clearly as possible. I will first give an overview of Ingarden's method, which relies mainly on a fascinating combinatorial analysis. Then, I will proceed to summarize his examination of possible solutions to the Controversy, and determine which ones can be ruled out on ontological grounds. Finally, I will explain why this ambitious project ultimately leads to a theoretical impasse, leaving Ingarden unable to come up with a definitive solution to the Controversy - regardless of the fact that the book is unachieved. I will argue that his analysis of the problem yields a more modest but nonetheless valuable result.

\section{INGARDEN'S COMBINATORIAL METHOD}

Ingarden's treatment of the Controversy closely follows his distinction between three foundational parts of philosophy: ontology, metaphysics and epistemology. The first step towards a solution thus consists in undertaking an ontological analysis of the problem, which is itself threefold. First, the existential-ontological analysis (carried out in the first volume of Controversy) has to explore existential moments and their possible combinations into different concepts of being. Then the formal-ontological analysis must shed some light on the form of the different kinds of entities revealed by the previous investigation: do they have the formal attributes of a thing, a process or a relation, and what are the formal boundaries of their mode of being? Finally, the material-ontological analysis is concerned with the qualitative determinations of entities, without which their form could not be "filled".

This ontological investigation is necessary but not sufficient to bring an end to the Controversy. Its fundamental purpose is to draw an exhaustive map of the possible solutions to the idealism-realism debate; existential, formal and material analyses should in turn rule out a lot 
of possibilities as inconsistent, until a reasonable number of alternatives is reached - or even a single hypothesis. This result must nonetheless be refined by a metaphysical investigation in order to find out which of the possible solutions discovered so far is the true one. Even if the previous step proves to be sufficient to bring down the number of possibilities to a single one, a metaphysical analysis is still required to confirm this result on factual grounds: whereas ontology explores the realm of pure possibilities (and the necessary connections between them), metaphysics studies how things actually are. Finally, an epistemological analysis is needed to validate metaphysical knowledge - as Ingarden puts it epistemology "aims at achieving a critique of factually acquired knowledge""1.

One might say that Ingarden's task in the first volume of Controversy is first and foremost a clarification: the Controversy has often been unduly reduced to a simplistic alternative, the socalled realism-idealism debate, with a limited understanding of the problem at hand. According to Ingarden, arguing over the existence of the world should not simply amount to asking whether the external world exists or not, but rather how it exists, if it does. In order to understand the various ways in which the world can stand relative to consciousness, and vice versa, one has to deploy a very fined-grained network of concepts pertaining to the mode of being of things in general. These conceptual units are called "existential moments": they determine the way in which a given entity exists in itself and relatively to other things. Naturally existential moments can be compatible or incompatible; for something to have incompatible existential moments is an ontological contradiction, and hence can be ruled out a priori of the realm of possibilities. Concepts of being themselves are maximally inclusive combinations of compatible existential moments. The existential-ontological analysis thus follows two steps: first it has to give a list of all existential moments, then it must determine all the meaningful combinations between compatible moments into distinct concepts of being. However these two steps alone are not sufficient to discover the possible solutions to the Controversy; a third step is required, which consists in finding out what existential moments the world and consciousness can respectively have without entailing a contradiction in the resulting metaphysical worldview ${ }^{2}$.

At the root of this combinatorial method lies a deep commitment to classical logic, and especially to the law of non-contradiction. Ruling out contradictions is the only way to narrow down the number of possibilities at the stage of the existential-ontological analysis, since Ingarden wants to proceed purely a priori, taking into account every possible combination however nonsensical it might seem at first glance. As a result of this meticulous method, Ingarden's examination of the Controversy is extremely intricate, if not somewhat tedious, and his arguments are sometimes difficult to follow. I shall try to give a clear outline of his meandering analysis, and reflect on the bigger picture emerging from the first volume of Controversy.

\section{BASIC EXISTENTIAL MOMENTS AND THEIR COMBINATIONS}

In the most general terms, the crux of the Controversy is to determine "whether a 'real' world (or any 'real' entity whatever) can be 'existentially independent' of, or 'dependent' on, pure consciousness" ". But this preliminary formulation centered on the concept of "existential dependence" is still too vague, for "the history of the problem is telling with regard to the

\footnotetext{
${ }^{1}$ Controversy, p. 83.

2 Such a combinatorial approach to the ontological problem of the relation between consciousness and the world is not entirely unprecedented. For instance, one can find a relatively similar method (using fewer combinations) in C. D. Broad, The Mind and Its Place in Nature, London, Routledge \& Kegan Paul, 1925, pp. 607-50. Naturally, Ingarden's phenomenological (transcendental) starting point is a significant difference between his approach and Broad's. 3 Ibid., p. 95.
} 
ambiguity of this expression" ${ }^{4}$. Indeed, there are no less than four different ways of understanding the ideas of dependence and independence in an ontological context. Ingarden sets out to define these four pairs of contradictory existential moments as a first step towards the clarification of the Controversy:

1) autonomy - heteronomy (Seinsautonomie - Seinsheteronomie);

2) originality - derivativeness (Seinsursprünglichkeit - Seinsabgeleitetheit);

3) selfsufficiency - non-selfsufficiency (Seinsselbständigkeit - Seinsunselbständigkeit);

4) independence - dependence (Seinsabbängigkeit - Seinsunabhängigkeit).

A given entity can only have one of the two moments of each pair ${ }^{5}$; I will briefly recall the definitions of these moments without dwelling on the details, as this is not the focus of the present chapter ${ }^{6}$. An entity is autonomous if it exists by itself, whereas it is beteronomous if the foundation of its being (Seinsfundament) is in something else. It is original if it exists necessarily (without being created), and derived if it is contingent and created by something else. It is selfsufficient if it does not need to be part of a greater whole in order to exist; and non-selfsufficient if it necessarily coexists in a whole with something else. Finally, a selfsufficient being is independent if it does not require the existence of another selfsufficient being for the continuation of its own existence, and dependent if it does (this distinction does not apply to non-selfsufficient entities). In order to show more precisely how these pairs of existential moments are related, it is helpful to use formal definitions and equivalence relations ${ }^{7}$ :

$$
\begin{aligned}
& \text { Heteronomous }(x, y)=_{\text {def }} x \neq y \text { and } x \text { has the foundation of its being in } y \\
& \forall x \operatorname{Autonomous}(x) \equiv \sim \exists y[x \neq y \wedge \operatorname{Heteronomous}(x, y)] \\
& \operatorname{Derived}(x, y)=_{\text {def }} x \neq y \text { and } y \text { creates } x \\
& \forall x \operatorname{Original}(x) \equiv \sim \exists y[x \neq y \wedge \operatorname{Derived}(x, y)] \\
& \forall x \forall y \text { Non-selfsufficient }(x, y) \equiv x \neq y \wedge \square \exists z(x<z \wedge y<z) \\
& \forall x \operatorname{Selfsufficient}(x) \equiv \sim \exists y[x \neq y \wedge \operatorname{Non}-\operatorname{selfsufficient}(x, y)] \\
& \forall x \forall y \operatorname{Dependent}(x, y) \equiv \square(\mathrm{E} ! y \rightarrow \mathrm{E} ! x) \\
& \forall x \text { Independent }(x) \equiv \sim \exists y[x \neq y \wedge \operatorname{Dependent}(x, y)]
\end{aligned}
$$

According to Ingarden, there are eight ways to combine these existential moments into noncontradictory "concepts of being" (Seinsbegriffe):

I. autonomy - originality - selfsufficiency - independence;

\footnotetext{
${ }^{4}$ Ibid., p. 109.

${ }^{5}$ They can also have none of the members of a pair in the case of non-selfsufficient beings, which are neither independent nor dependent.

${ }^{6}$ For a good overview of existential moments, see I. Johansson, "The Basic Distinctions in Der Streit", Semiotica, 194, pp. 137-157; and A. Chrudzimski, 2015, "Ingarden on Modes of Being", in Br. Leclercq, S. Richard and D. Seron (eds.), Objects and Pseudo-Objects: Ontological Deserts and Jungles From Brentano to Carnap, Berlin, De Gruyter, pp. 199-222. 7 In what follows, the mereological relation " $<$ " is to be read as "is a part of" and the predicate "E!" means "to exist" (these formal definitions are partially inspired by Chrudzimski, op. cit.). I have systematically formalized the "negative" existential moments as relations, since they are always relativized to another entity or domain of being, while their "positive" counterparts are used by Ingarden as predicates in an absolute manner (for instance if a given entity is non-selfsufficient it is so only with respect to another entity, whereas if it is selfsufficient it is so absolutely).
} 
II. autonomy - derivativeness - selfsufficiency - independence;

III. autonomy - originality - non-selfsufficiency;

IV. autonomy - originality - selfsufficiency - dependence;

V. autonomy - derivativeness - selfsufficiency - dependence;

VI. autonomy - derivativeness - non-selfsufficiency;

VII. heteronomy - derivativeness - selfsufficiency - dependence;

VIII. heteronomy - derivativeness - non-selfsufficiency.

From here, things get a little more complicated, as Ingarden applies this analysis to the resolution of the Controversy. The initial formulation of the problem was whether the real world is existentially dependent or independent vis-à-vis pure consciousness ("real world" and "pure consciousness" are understood here as the two domains of being that one can discriminate from the standpoint of immanent perception by adopting a phenomenological attitude). Ingarden can now frame the issue in a much more detailed way, armed with his four pairs of existential moments and with the eight concepts of being they constitute. The problem now amounts to discovering the mode of being of the real world and of pure consciousness respectively, which have to be compatible, as well as the relations that might obtain between the two domains. Since ontology is merely concerned with pure possibilities and necessary connections, this means that he has to examine every single combination of concepts of being for pure consciousness and the real world (whether they have the same or a different one). And since eight concepts of being have been discovered so far, this yields no less than $8^{2}=64$ combinations. The two tables below should make the variables of this complex combinatory analysis clearer; the first one lists the eight possible existential configurations of the real world relatively to pure consciousness, with the name of each position in Ingarden's terminology, and the second one similarly lists the possible configurations of pure consciousness vis-à-vis the real world, divided by Ingarden in eight nameless groups.

\begin{tabular}{|l|c|c|c|c|}
\cline { 2 - 4 } \multicolumn{1}{c|}{} & \multicolumn{3}{c|}{ The real world is... } \\
\cline { 2 - 5 } \multicolumn{1}{c|}{} & autonomous & original & selfsufficient & independent \\
\hline Absolute Realism (AR) & yes & yes & yes & yes \\
\hline Absolute Creationism (AC) & yes & no & yes & yes \\
\hline Dualist Unity Realism (DUR) & yes & yes & no & $/$ \\
\hline Dependence Realism (DR) & yes & yes & yes & no \\
\hline Realist Dependence Creationism (RDC) & yes & no & yes & no \\
\hline Realist Unity Creationism (RUC) & yes & no & no & $/$ \\
\hline Idealist Dependence Creationism (IDC) & no & no & yes & no \\
\hline Idealist Unity Creationism (IUC) & no & no & no & $/$ \\
\hline
\end{tabular}

Table 1

\begin{tabular}{|l|c|c|c|c|}
\cline { 2 - 5 } \multicolumn{1}{c|}{} & \multicolumn{3}{c|}{ Pure consciousness is... } \\
\cline { 2 - 5 } \multicolumn{1}{c|}{} & autonomous & derived from the real world & selfsufficient & independent \\
\hline Group I & yes & $n o$ & yes & yes \\
\hline Group II & yes & no & yes & no \\
\hline Group III & yes & yes & yes & yes \\
\hline Group IV & yes & yes & no & $/$ \\
\hline Group V & yes & no & no & $/$ \\
\hline Group VI & yes & yes & yes & no \\
\hline Group VII & no & yes & no & $/$ \\
\hline Group VIII & no & yes & & \\
\hline
\end{tabular}

Table 2 
For the sake of clarity, I will introduce the following notation: each solution will be abridged by the initials of the underlying position (from Table 1) followed by the Roman numeral corresponding to its group (from Table 2). For instance, "AR-III" stands for the variant of Absolute Realism found in the third group of possible solutions to the Controversy. This way, for each solution, the letters indicate which existential moments the real world is assumed to have, while the Roman numeral similarly indicates which existential moments pure consciousness is assumed to have. This notation should make it easier to remember the exact postulates of each possible solution by looking at the two tables above.

\section{THE FIRST STAGE OF THE EXISTENTIAL ANALYSIS: ASSESSING 64 COMBINATIONS}

I will briefly review each group of solutions, following Ingarden's own order of examination. In each group, a lot of hypothetical solutions can be ruled out on existential grounds, because their combination entails an ontological contradiction in one way or another. This is how Ingarden brings down the number of admissible solution from 64 to $15^{8}$.

The first group is composed of the solutions sharing the following assumption about pure consciousness:

Assumption I. Pure consciousness is autonomous, not derived from the real world, selfsufficient and independent vis-à-vis the real world.

Two solutions out of eight are deemed inadmissible in this group: Dualist Unity Realism (DUR-I) and Dependence Realism (DR-I). Ingarden's explanation of the contradiction plaguing the former is somewhat confusing. According to DUR-I, the real world must coexist in a whole with pure consciousness; but the real world is also supposed to be original, thus it is a necessary being, while it is assumed that pure consciousness is not derived from the real world. Ingarden adds that pure consciousness is unlikely to be original; if not, then it is derived from something else than the real world, a "third factor". Since the real world, a necessary existent, can only be required to coexist in a whole with another necessary existent, pure consciousness must owe the necessity of its own existence to this third factor from which it is derived. But Ingarden still finds this picture unconvincing, because the existence of the real world would still depend, in a way, on another being (by being non-selfsufficient vis-à-vis pure consciousness). This is why, according to him, DUR-I can be ruled out on existential grounds. Ingarden makes two assumptions in this demonstration: first, that pure consciousness is not original, and second that a given entity can only be non-selfsufficient relatively to another if it is derived while the second is original. One could argue that both of these assumptions go beyond the scope of an existential-ontological analysis. The first one is in fact motivated earlier, in the $\$ 18$ of Controversy, where Ingarden mentions the phenomenon of sleep - during which consciousness temporarily falls out of existence. He argues that the sheer possibility of the disappearance of consciousness should rule out its originality, since original beings exist necessarily, hence eternally. The second assumption is justified by the following biconditional, which is endorsed by Ingarden as what we will call an "existential axiom":

(1) $\forall x \forall y$ [Non-selfsufficient $(x, y) \equiv \sim \operatorname{Original}(x) \& \operatorname{Original}(y)]$

\footnotetext{
8 This analysis is carried out in $\$ \$ 18-26$ of Controversy.
} 
However, Ingarden himself admits in his ontology a class of entities which are both original and non-selfsufficient, namely ideal states of affairs ${ }^{9}$. Thus he seems to implicitly assume that the world is not merely composed of ideal states of affairs, even if he does not clearly explains why this should be the case (this hypothesis will nonetheless be confirmed by the formal-ontological analysis of the real world).

Unfortunately, the case of DR-I is not really more straightforward. According to DR-I, the real world depends on pure consciousness for its continued existence. Ingarden applies to this case the same reasoning: since the real world is assumed to be original, its existence cannot depend on another being ${ }^{10}$. This validates the following entailment:

\section{(2) $\forall x \forall y[\operatorname{Dependent}(x, y) \rightarrow \sim \operatorname{Original}(x)]$}

Here too, there seems to be an inconsistency: Ingarden also admits in his ontology entities which are both original and dependent, namely ideal relations. Even if the assumption that the world is not entirely composed of ideal relations seems relatively unproblematic ${ }^{11}$, it does not strictly fall within the scope of an existential-ontological analysis.

The six admissible solutions from the first group are slightly easier to grasp. The first variant of Absolute Realism, AR-I, is a very strong kind of dualism: both pure consciousness and the real world are autonomous, original (or at least, in the case of consciousness, not derived from the world), selfsufficient and independent. In other words, both are necessary beings, and neither depends in any way on the other: pure consciousness could exist without the real world, and vice versa. The first variant of Absolute Creationism, AC-I, is similar in every respect except for the fact the real world is not original but derived from pure consciousness. This means that consciousness literally creates the world as an autonomous being (as opposed to some kind of purely intentional being). Ingarden notes that this solution has never been seriously advocated by anyone in the history of philosophy, although he adds that it might bear a (misleading) resemblance with Hegel's so-called "objective idealism" ${ }^{12}$. The first version of Realist Dependence Creationism (RDC-I) is a related view according to which pure consciousness creates the world as existentially dependent from it. Ingarden remarks that this theory is analogous to the versions of theological creationism admitting the doctrine of creatio continua (the world is not only created by God, but also permanently depends on Him for its continued existence). But here too, it is hard to think of any advocate of the view when we substitute "God" for "consciousness". The first variant of Realist Unity Creationism (RUC-I) is even more puzzling: pure consciousness creates the world as non-selfsufficient relative to it. This means that the real world is not only derived from pure consciousness but necessarily coexists with it in the unity of a whole - while still being autonomous. Ingarden does not say much about the details of this solution. The concept of being of the real world according to Realist Unity Creationism coincides with what later chapters of Controversy define as the concept of being of

\footnotetext{
9 See the appendix for a synoptic overview of Ingarden's ontology. The "existential axioms" hold for existential moments regarding the real world and pure consciousness, but one should bear in mind that they do not necessarily hold for any entity.

${ }^{10}$ In the original Polish version of Controversy (henceforth Spór), Ingarden merely says that an original entity cannot depend on a derivative entity; however, I have chosen to focus on the German version in this chapter (henceforth Streit), since it can be considered as Ingarden's last word on the matter. Besides, his justification of the existential axiom (2) in Streit is quite convincing: since an original entity exists necessarily, it is doubtful that it can depend existentially on another entity, be it original itself. This is why the case of ideal relations can seem rather problematic. 11 One might try to advocate a kind of relational idealism or "panrelationalism" according to which the world is indeed entirely composed of ideal relations. The problem with such a view is that according to Ingarden ideal relations are original but nonetheless dependent on their relata. But if the world is merely constituted by relations, what would these relata be? The only option is to say that the relata of the world's relational constituents are conscious experiences themselves, but this hardly makes any sense. In any case, the formal analysis of the real world will rule out the possibility of such a far-fetched hypothesis.

12 Controversy, p. 175.
} 
real events and individual properties (tropes): events and properties are indeed autonomous, derivative and non-selfsufficient, because they coexist in a larger whole (processes for events, individual objects for properties) ${ }^{13}$. This is hardly helpful to understand RUC-I, but its putative impossibility can only be decided by a formal analysis.

The last two admissible solutions of the first group are different, because they assume the "real" world to be heteronomous; in other words, they venture into the territory of idealism. According to Idealist Dependence Creationism (IDC-I), pure consciousness creates the real world as a heteronomous being which existentially depends on it. Ingarden believes that this solution is very close to Husserl's transcendental idealism. Idealist Unity Creationism (IUC-I) is similar except for the assumption that the real world is non-selfsufficient (rather than dependent) vis-à-vis pure consciousness. This is simply an idealist version of RUC-I, and the same questions regarding the interpretation of the world's non-selfsufficiency arise again, although they seem less puzzling once we admit that the world is merely heteronomous. According to Ingarden, the closest historical doctrine to IUC-I can be found in Berkeley's immaterialism. It is worth noting in passing that Ingarden does not seriously consider a third kind of idealism, namely what we can call "Idealist Independence Creationism", according to which the world is heteronomous, selfsufficient and derived from pure consciousness, but also independent from it - meaning that it does not requires it for its continued existence. He does concede that the impossibility of such a solution cannot be ruled out on existential grounds: only a material analysis of pure consciousness can tell us whether a heteronomous object derived from conscious experiences requires the enactment of such experiences simply for its genesis or also for its continued existence. Ingarden conjectures that the latter is true, but there also seems to be an existentialontological motivation for the rejection of such a view: if a given entity is heteronomous, not only should it be derivative, but it should also be dependent - for how could something have the foundation of its existence outside itself and yet be existentially independent? This is true in virtue of two other existential axioms already mentioned in $\$ 16$ of Controversy:

(3) $\forall x \forall y[\operatorname{Heteronomous}(x, y) \rightarrow \operatorname{Derived}(x, y)]$

(4) $\forall x \forall y[\operatorname{Heteronomous}(x, y) \wedge \operatorname{Selfsufficient}(x) \rightarrow \sim \operatorname{Independent}(x)]$

There is one additional and unique solution in the first group: the so-called "Negative Solution", according to which the real world does not exist. Ingarden does not consider nonbeing as a distinct concept of being, but rather as the privation of all existential moments. This "solution" to the Controversy, beyond both realism and idealism, amounts to denying any kind of intentionality to consciousness. Conscious experiences would have no directedness towards anything; it would be, so to speak, only directed "inwards" - although this formulation is also deficient since it conveys the idea of some kind of conscious activity. It is hard to get a grip on the Negative Solution, as Ingarden himself admits, for we are constantly tempted to interpret it as an idealist position according to which the world is merely heteronomous. Ingarden mentions that the closest historical doctrine is to be found in Ernst Mach's phenomenalism, but this is only a superficial similitude because neutral monism abolishes the distinction between consciousness and the world.

Having reviewed each position as it appears in the first group of solutions, it will be easier to examine the seven remaining groups of solutions. The second group starts with the following assumption:

Assumption II. Pure consciousness is autonomous, not derived from the real world, selfsufficient and dependent on the real world.

${ }^{13}$ See the appendix. 
In this group, only two solutions are admissible on existential grounds: AR-II and DR-II. AR-II stems from the assumption that pure consciousness is autonomous, selfsufficient, not created by the real world but nonetheless dependent on it for its continued existence, while the real world itself is autonomous, original, selfsufficient and independent. Recall that Ingarden has previously introduced the following axiom:

(2) $\forall x \forall y[\operatorname{Dependent}(x, y) \rightarrow \sim \operatorname{Original}(x)]$

This entailment applies to the real world, but there is no reason why it should not apply to pure consciousness as well. As previously noted, only ideal relations violate (2), and it would be certainly difficult to conceive how conscious experiences might be ideal relations. Besides, Ingarden has already assumed that pure consciousness is not original, and he used this assumption to rule out DUR-I. Therefore, in AR-II consciousness existentially depends on the real world, but is derived from something else (e.g. God).

DR-II assumes that pure consciousness and the real world are mutually dependent. Applying the axiom (2), this means that a slight modification must be made in the assumptions of Dependence Realism in order to make this solution admissible: the real world is not original in the strict sense, but merely not derived from pure consciousness ${ }^{14}$. Both pure consciousness and the real world are thus created by something else, whether it is the same third factor or two distinct domains. Since they are mutually dependent from an existential point of view, DR-II makes a little more sense if we suppose that a single third factor, such as God, has created both of them as such. Indeed, in order to be mutually dependent, pure consciousness and the real world must be created at the exact same time, since they require each other for their continued existence. DR-II thus seems compatible with a particular kind of theism according to which God creates the world and pure consciousness in such a way that the annihilation of one entails the annihilation of the other. This is, to say the least, an original theory.

Other solutions from the second group are easily ruled out. Variants of creationism and idealism (AC-II, RDC-II, RUC-II, IDC-II and IUC-II) are straightforwardly contradictory because pure consciousness cannot depend on a world that it has itself created, in virtue of the following existential axiom:

(5) $\forall x \forall y[\operatorname{Derived}(x, y) \rightarrow \sim \operatorname{Dependent}(y, x)]$

Likewise, DUR-II is impossible because pure consciousness cannot depend on the real world if the latter is required to coexist with it in a whole:

(6) $\forall x \forall y[\operatorname{Dependent}(x, y) \rightarrow \operatorname{Selfsufficient}(x) \wedge \operatorname{Selfsufficient}(y)]$

This entailment is evident from the definition of existential moments: only selfsufficient entities can be either dependent or independent.

The third group assumes that pure consciousness is derived from the real world:

Assumption III. Pure consciousness is autonomous, derived from the real world, selfsufficient and independent vis-à-vis the real world.

In this group, only Absolute Realism (AR-III) is admissible. It is, in a way, the symmetrical position of AC-I: the real world creates pure consciousness, but the latter remains autonomous, selfsufficient and independent. This means that it does not require the world for the continuation of its existence, but only for its creation. All the other solutions of this group can be dismissed. Creationist and idealist solutions (AC-III, RDC-III, RUC-III, IDC-III and IUCIII) are ruled out because if pure consciousness is derived from the real world, the opposite is obviously false (existential derivation is clearly not a symmetric relation):

\footnotetext{
${ }^{14}$ We will come back later to the significance of this alteration.
} 
(7) $\forall x \forall y[\operatorname{Derived}(x, y) \rightarrow \sim \operatorname{Derived}(y, x)]$

DUR-III is ruled out because pure consciousness cannot be derived from the real world if the latter is non-selfsufficient with respect to it (in order for $y$ to create $x$, it must be able to exist without $x$, thus excluding the necessity of its coexistence with $x$ in a whole):

(8) $\forall x \forall y[\operatorname{Derived}(x, y) \rightarrow \sim$ Non-selfsufficient $(y, x)]$

Finally, DR-III is ruled out for the same reason which already plagued five solutions of the second group, in virtue of the axiom (5) - if pure consciousness is derived from the real world, the latter cannot depend on it.

The fourth group is easy to review: it maintains the assumption that pure consciousness is derived from the real world, while adding that it also depends on it.

Assumption IV. Pure consciousness is autonomous, derived from the real world, selfsufficient and dependent on the real world.

Since pure consciousness is still assumed to be derived from the real world, all the solutions are ruled out except AR-IV, for the same reasons than in the third group. AR-IV, however, is an interesting and familiar position: the world can exist on its own, but if consciousness exists it is not only derived from the world, but also dependent on it. Ingarden notes that this solution is close to the materialist worldview, and in particular to what he labels "epiphenomenalism". It is worth insisting on the fact that according to such a view, the existence of matter does not necessarily bring about consciousness, since it can exist without it. Consciousness is a mere "epiphenomenon" of the world, and its existence is contingent. However, Ingarden adds that the analogy with a materialist form of epiphenomenalism is superficial, for the "real world" is not entirely material. Indeed, the materialist only wants to attribute "absolute being" (i.e. autonomy, originality, selfsufficiency and independence) to matter, not to the whole real world, which can also include ideal objects for instance. This important precision means that material epiphenomenalism is only a special instance of AR-IV, but it does not rule it out. After all, the generic description of AR-IV does not specify exactly what creates pure consciousness and on what it depends: it could either be the whole real world, or simply some part of it. In the latter case, it could be the material world - and this is a very sensible hypothesis. Such a theory is still popular in contemporary philosophy of mind, under the guise of emergentism. It should also be noted that Ingarden's mentions of "epiphenomenalism" and "materialism" are ambiguous; indeed, according to AR-IV, pure consciousness is existentially autonomous. It really exists, and really has the properties it is assumed to have. Even if it turns out that the real world is entirely physical, the fact that a non-physical existential domain such as pure consciousness exists autonomously means that AR-IV is incompatible with what contemporary philosophers call "physicalism" - the idea that everything is physical, or alternatively that only physical entities exist. Thus this solution might be called "materialist" in some cases if it merely means that consciousness emerges from matter, not that everything is matter: emergentism is perfectly compatible with dualism ${ }^{15}$. Therefore AR-IV appears as a strong candidate to resolve the Controversy.

The fifth group of solutions starts with the postulate that pure consciousness is nonselfsufficient with regard to the world:

Assumption V. Pure consciousness is autonomous, not derived from the real world, and non-selfsufficient vis-à-vis the real world.

Two solutions are admissible in this group: Absolute Realism (AR-V) and Realist Unity Creationism (RUC-V). AR-V supposes that pure consciousness necessarily coexists in a whole with the real world, while the latter is selfsufficient and independent relative to it. Such an

\footnotetext{
${ }^{15}$ See below the analysis of AR-VII for a "physicalist" counterpart of AR-IV.
} 
asymmetry can seem problematic: the "mereological bond" between consciousness and the world is necessary for the first but contingent for the second. Recall that in his examination of DUR-I, Ingarden had implicitly appealed to the following biconditional as an existential axiom:

(1) $\forall x \forall y[\operatorname{Non}-\operatorname{selfsufficient}(x, y) \equiv \sim \operatorname{Original}(x) \& \operatorname{Original}(y)]$

Since pure consciousness is supposed not to be derived from the real world in AR-V, this means that it is derived from a third factor, which has to be original itself. Thus pure consciousness is created by a third factor in such a way that it needs to coexist in a whole with the real world, while the real world can exist on its own. As Ingarden admits, there are a lot of open questions surrounding this solution, but these can only be answered by a material-ontological analysis.

RUC-V offers a more complex picture: pure consciousness creates the real world, while they both are non-selfsufficient with regard to each other. This combination is apparently problematic: in order for pure consciousness to create the real world, it has to exist, but since it is also non-selfsufficient vis-à-vis the real world it needs it to exist in the first place. Ingarden considers that one cannot rule out this solution on existential grounds, but he does not explain clearly why this is the case, even in the original Polish version of Controversy in which he dedicates more space to this solution. Even worst, Ingarden seems to contradict himself, because as we have seen he has already rejected DUR-III by appealing to the following entailment:

(8) $\forall x \forall y[\operatorname{Derived}(x, y) \rightarrow \sim$ Non-selfsufficient $(y, x)]$

This should straightforwardly rule out RUC-V, in which the real world is derived from pure consciousness while the latter is non-selfsufficient relative to it. In fact, Ingarden also appeals to (8) to rule out another solution of the fifth group, namely $\mathrm{AC}-\mathrm{V}$, according to which pure consciousness creates the real world and is non-selfsufficient relative to it, while the real world is selfsufficient. The only difference in RUC-V is that the non-selfsufficiency is reciprocal - but why should this detail save the solution? If we follow Ingarden, we should modify (8) in the following way:

(8*) $\forall x \forall y[\operatorname{Derived}(x, y) \wedge \sim \operatorname{Non}-\operatorname{selfsufficient}(x, y) \rightarrow \sim \operatorname{Non}-\operatorname{selfsufficient}(y, x)]$

But $\left(8^{*}\right)$ is ultimately unwarranted: it looks like an ad hoc axiom to save RUC-V and prevents Ingarden from committing a fallacy. Even with a charitable reading of the text, it is hard to see why RUC-V should be deemed admissible on existential grounds, as this seemingly threatens the consistency of the whole analysis.

The rest of the solutions from the fifth group are ruled out by Ingarden. I have already mentioned that Absolute Creationism (AC-V) is disqualified precisely because of (8). Dependence Realism (DR-V), according to which pure consciousness is non-selfsufficient vis-àvis the real world while the latter is dependent on it, is ruled out in virtue of the axiom (6). The same axiom also undermines both variants of dependence creationism (RDC-V and IDC-V), which assume that the real world is derived from pure consciousness and dependent on it, while pure consciousness is non-selfsufficient relative to the world. Idealist Unity Creationism (IUC-V) is an interesting case, because it is similar to RUC-V in every respect except for the fact that the real world is also supposed to be heteronomous. Here Ingarden seems to concede that this solution can simply be ruled out by appealing to (8) - in which case RUC-V should also be ruled out - but he adds that it should be ruled out anyway in virtue of the following axiom:

(9) $\forall x \forall y[$ Autonomous $(x) \wedge \sim \operatorname{Autonomous}(y) \rightarrow \sim \operatorname{Non}-\operatorname{selfsufficient}(x, y)]$

It seems indeed difficult to admit that an autonomous entity and a heteronomous one could coexist within the unity of a single whole, let alone necessarily coexist in such a way.

This leaves us with the case of Dualist Unity Realism (DUR-V). This solution is interesting because its configuration is quite similar to that of DR-II, which Ingarden had judged admissible 
on existential grounds, while he dismisses DUR-V. According to DUR-V, pure consciousness and the real world are mutually non-selfsufficient, while they are both autonomous and not derived from each other. In virtue of the existential axiom (1), this means that neither pure consciousness nor the real world can be original. On the face of it, then, RUC-V is contradictory, since the real world is supposed to be original. But just like in the case of DR-II, a weakened version seems to be admissible, in which the world is merely not derived from consciousness. Pure consciousness and the real world would be both created by a something else, probably by the same third factor, in such a way that they are mutually non-selfsufficient. A simple way to picture this view is to imagine that some absolute being (e.g. God) creates a whole constituted by pure consciousness and the real world, such that the parts must belong to the whole in order to exist. Surprisingly, Ingarden does not mention this possibility, even though he has stated in his examination of DR-II that only a material investigation can determine whether the real world is original or merely not derived from pure consciousness. This is why he had cautiously concluded that the weakened version of DR-II, according to which both existential domains are derived from a third factor, is "possibly not inadmissible from the existential point of view" for the sake of coherence, the weakened version of DUR-V must also be judged admissible, despite Ingarden's hasty dismissal ${ }^{17}$.

The sixth group assumes that pure consciousness is not only non-selfsufficient, but also created by the real world:

Assumption VI. Pure consciousness is autonomous, derived from the real world, and nonselfsufficient vis-à-vis the real world.

Once again, only Absolute Realism (AR-VI) is admissible in this group. According to this solution, the real world - which is autonomous, original, selfsufficient and independent - creates pure consciousness in such a way that it necessarily coexists with it in a whole. It is not obvious to see how this position differs from AR-IV (according to which consciousness is selfsufficient but existentially depends on the world). The problem is that the non-selfsufficiency of pure consciousness vis-à-vis the real world might seem a little mysterious. On the face of it, AR-VI appears to be compatible with a kind of dual aspect theory according to which fundamental properties are both mental and physical, meaning that the mental and the physical do "coexist in a whole". Such a theory would also be consistent with AR-V; but in both cases we only have what Ingarden calls a "unilateral" non-selfsufficiency, meaning that the real world could exist outside of a whole including pure consciousness. Note that this is not the case of DUR-V, which displays a symmetrical non-selfsufficiency and thus is in principle the best existential model for a dual aspect theory (or neutral monism on some interpretations of it). The theory of property dualism, in its emergentist version, might be a better fit for AR-VI. In any case, the details of AR-VI are left to a material-ontological investigation.

All the variants of creationism (AC-VI, RDC-VI, RUC-VI, IDC-VI, IUC-VI) are obviously contradictory in this group, because if pure consciousness is derived from the real world it cannot be the other way around - see the axiom (7). Dualist Unity Realism (DUR-VI) is impossible in virtue of the axiom (1): if the real world is original, it cannot be non-selfsufficient. Finally, Dependence Realism (DR-VI) is ruled out because of the axiom (6): the real world's dependence on pure consciousness presupposes the selfsufficiency of both.

The last two groups of possible solutions to the Controversy are special because they both assume that pure consciousness is heteronomous. Ingarden regards this assumption as inconsistent with the phenomenological data. In the $\$ 18$ of Controversy, he endorses the assumption that "the pure experiences under consideration are autonomous"18, but adds in a

\footnotetext{
${ }^{16}$ Controversy, p. 200.

${ }^{17}$ I shall come back to the issue of the "weakened versions" in the section 5 .

${ }^{18}$ Controversy, p. 168.
} 
footnote that "the time will come when we drop this assumption" examination of the seventh and eighth groups, he mentions that they appear to be ruled out by experience. He nevertheless makes some remarks about the solutions of these groups. What does it mean, exactly, to say that pure consciousness is heteronomous? The "reality" of a heteronomous entity is only bestowed upon it by some kind of enactment; for instance, the purely intentional object "Hamlet" is conceived as a "real" object having the property of being a man by means of a conscious act which enacts the content of a literary work of art. But Hamlet is not a real, persistent object; the foundation of its being is not in itself, but a conscious act of presentation. However a heteronomous entity is not necessarily an intentional object: it does not necessarily depends on some kind of conscious act. For instance, empirically possible objects, events and properties are heteronomous: they are not real, but they still exist in a lesser way. This might help us to make sense of the hypothesis that pure consciousness is heteronomous; it implies that consciousness as we experience it is nothing more than some kind of illusion, meaning that the properties we attribute to it, even from a philosophical standpoint, are not properties it really has but merely properties it seems to have - just like a possible horse does not really instantiate the property of being a real horse. Ingarden believes that such a hypothesis is absurd because it is ruled out by experience: we experience consciousness as an autonomous existential domain. Other philosophers and scientists, however, strongly disagree with this opinion. Some have argued extensively, for instance, that subjective consciousness is simply an elaborate illusion generated by a specialized neural network in the human brain ${ }^{20}$. More generally, reductive physicalism is an umbrella term for theories according to which the mental is in some way entirely reducible to the physical. This does not mean, in Ingarden's lexicon, that they do not exist at all, for we are still tricked into believing that we are undergoing such states, and that they are real; it seems fairer to characterize this view as advocating the heteronomy of consciousness. Moreover, Ingarden does not clearly explain how we are supposed to experience the autonomy of pure consciousness; after all, the defining feature of an illusion is that it mystifies us. All in all, the dismissal of the last two groups of possible solutions on the basis of experience is at least controversial, and as such they are worthy of examination. Besides, Ingarden himself acknowledges the popularity of theories advocating something like the existential heteronomy of consciousness:
"A form of materialism shows up in the annals of philosophy, especially of the $19^{\text {th }}$ century, in which consciousness is not only regarded as something whose existence is considered in some indeterminate sense 'meaner' or 'weaker' than the existence of matter. It is said in this connection that consciousness is a kind of 'phosphorescence' of matter, an epiphenomenon of the latter, or even a 'function' of the highly organized matter. Yet what this is all supposed to mean is neither stated, nor further investigated. One also does not employ the concept of heteronomy in this context, and this for the sole reason that materialism does not carry out any sort of analysis of mode of being. Despite this, it would appear that the dominant tendency in materialism is to essentially degrade the being of consciousness in comparison with the being of matter ${ }^{21}$."

The seventh group assumes that the heteronomous pure consciousness depends on the real world:

Assumption VII. Pure consciousness is heteronomous, derived from the real world, selfsufficient and dependent on the real world.

In this group, Absolute Realism (AR-VII) is not ruled out on existential grounds. It is essentially a variation on AR-IV (the "epiphenomenalist" view), except for the fact that pure consciousness is now supposed to be merely heteronomous. According to this view, the mode of being of

\footnotetext{
${ }^{19}$ Ibid.

${ }^{20}$ Cf. Th. Metzinger, 2003, Being No One: The Self-Model Theory of Subjectivity, Cambridge (Mass.), MIT Press.

${ }^{21}$ Controversy, p. 219.
} 
conscious experiences is similar to the one of purely intentional objects or processes. AR-VII is probably best understood as a general framework for reductive physicalism, allowing the possibility of explaining the phenomenon of consciousness in purely physical terms. It might be suitable in particular for a functionalist approach to consciousness, since Ingarden takes processes to be precisely derivative, selfsufficient and dependent. Functionalism is the idea that mental states are best understood in terms of their functional role, which can be realized by different underlying physical systems - be it a silicon-based processor in a computer or an assembly of neurons in a biological brain - as long as they have the adequate structure. Ingarden himself hints at this idea in the previously quoted passage, when he speaks of consciousness as a function of highly organized matter. If the mental is a mere function of the physical, then it is indeed heteronomous, derived, selfsufficient and dependent: consciousness is a process, but has the foundation of its being in the structure of the world (or at least some parts of the world, such as the nervous system). It is not a "real" process like the movement of a physical body from one point to another, but a heteronomous one, which existentially depends on its realization by physical processes such as the firing of neurons.

The rest of the solutions from the seventh group are inadmissible. All variants of realist creationism (AC-VII, RDC-VII and RUC-VII) are obviously dismissed because an autonomous entity cannot be derived from a heteronomous one:

(10) $\forall x \forall y[\operatorname{Derived}(x, y) \wedge \operatorname{Autonomous}(x) \rightarrow \operatorname{Autonomous}(y)]$

Dualist Unity Realism (DUR-VII) is ruled out because an autonomous entity cannot coexist with a heteronomous entity in a single whole - see the axiom (9). The two variants of idealist creationism (IDC-VII and IUC-VII) are straightforwardly disqualified in virtue of the axiom (7): pure consciousness, being derived from the real world, cannot create it. Finally, Dependence Realism (DR-VII) is ruled out because the real world cannot depend on pure consciousness if it creates it - see the axiom (5).

The eighth and final group of solutions starts with the assumption that the heteronomous pure consciousness is non-selfsufficient relative to the real world:

Assumption VIII. Pure consciousness is heteronomous, derived from the real world and nonselfsufficient vis-à-vis the real world.

Once more, Absolute Realism (AR-VIII) is the only admissible solution in this group. It is a variation on AR-VI, according to which consciousness is derived from the world and needs to coexist with it in a whole, only in the present case consciousness is also heteronomous. Being both derivative and non-selfsufficient, consciousness is again best understood as a set of mental properties needing to coexist with objects in the world. This is also a very interesting solution, because it comes closest to what contemporary philosophers of mind call "supervenience physicalism". According to this generic theory, everything is physical and mental properties supervene on the physical. In other words, no two possible worlds can differ in their physical properties without differing in their mental properties as well. Supervenient properties are merely global or higher order properties of a given base; in the current case, mental properties are global properties supervening on the basic physical structure of the world, but they do not have any kind of existence independently of this structure. The relation of supervenience captures both the idea of derivation and the idea of dependence in Ingarden's vocabulary: if $y$ supervenes on $x$, then $y$ cannot exist without $x$. But it also captures the concept of heteronomy: a supervenient entity does not have the foundation of its being in itself, but in what it supervenes on. All the other solutions from the eighth group are ruled out for the exact same reasons as in the previous group.

If my interpretation of AR-VII and AR-VIII is correct, then not only these solutions are worth considering, but they are also the most widespread ones in contemporary philosophy of mind. It is only right that they should join the ranks of the admissible solutions to the 
Controversy, even if Ingarden includes them somewhat reluctantly and as if he was reasoning per absurdum for the sake of the completeness of his analysis. Looking back at the initial list of the eight generic positions regarding the real world and the eight groups of assumptions regarding pure consciousness, one might notice that a ninth combination has been left out in each. This corresponds to the cases where pure consciousness or the real world is heteronomous, selfsufficient and independent. However, such cases are left out for a good reason: they are impossible, because heteronomous entities can be either non-selfsufficient or dependent (if they are selfsufficient $)^{23}$. There is no such thing as an independent heteronomous entity:

\section{(11) $\forall x[\sim \operatorname{Autonomous}(x) \wedge \sim$ Non-selfsufficient $(x) \rightarrow \exists y \operatorname{Dependent}(x, y)]$}

This single axiom rules out no less than 17 additional solutions that shall therefore remain nameless. But Ingarden also takes into account an additional set of cases which he refers to as "double solutions". Double solutions are hybrid, because they intertwine ontological and epistemological concerns. Ingarden tries to give a better idea of this peculiar category by analyzing two examples, found respectively in Kant and Bergson. According to him, Kant advocated a combination of Absolute Realism and Idealist Dependence Creationism: pure consciousness creates the phenomenal world, which is heteronomous, selfsufficient and dependent on it. But there is also the "real world" of things in themselves, which is autonomous, original, selfsufficient and independent. It is safe to assume that the variant of Absolute Realism which best characterizes the relation between the real world and pure consciousness is AR-II, given that consciousness existentially depends on things in themselves (if the latter are a necessary condition of conscious experience). In any case, this interpretation of Kantianism is at least very debatable. As Ingarden himself admits, Kant's outlook on the Controversy has an epistemological starting point; for this reason, so-called "double solutions" appear to be nothing more than poor attempts at translating epistemological issues in a strictly ontological idiom. Ingarden often underlines that Husserl's main mistake was to give the priority to epistemology over ontology; his own philosophical project can be seen as an effort to stand Husserl on his head, as it were, in order to restitute the primacy of ontology over both metaphysics and epistemology. Existential moments are ontological concepts: they serve the purpose of defining several kinds of existential dependence, rather than epistemic dependence. Therefore it seems that Ingarden, in addressing these cases of "double solutions", ignored his own warning against the conflation of epistemological and ontological concerns.

Let us assess the outcome of this investigation so far. Ingarden started with 64 solutions, out of which 49 were ruled out. This leaves us with 15 admissible simple solutions to the Controversy, plus one negative solution and an indefinite number of "double-solutions" (which can be ignored). There are already some issues with this preliminary result: I have shown that Ingarden's reasoning is somewhat confused in his examination of the fifth group, since he admits a solution that he should logically reject (RUC-V), while he dismisses one that he should save at least in its weakened version (DUR-V). I will set this mistake aside for now, in order to give a clear outline of Ingarden's own conclusions. The 15 solutions that have not been ruled out yet according to him are summed up in Fig. 1 below.

This is not, however, the end of the existential-ontological analysis. They are still many solutions left because some additional existential moments have not yet been taken into account, namely the ones which are related to the analysis of time. With the help of these additional moments, Ingarden hopes to bring down the number of admissible solution below 15.

\footnotetext{
${ }^{23}$ Recall that only a selfsufficient entity can be dependent or independent.
} 


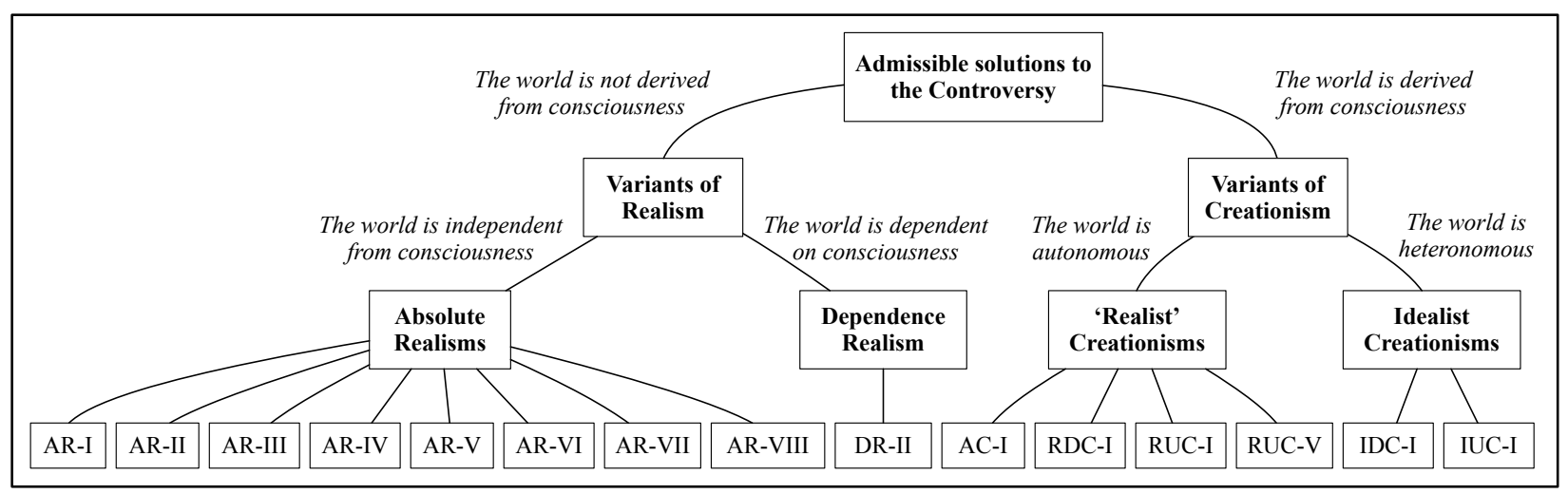

Fig. 1

\section{THE SECOND STAGE OF THE EXISTENTIAL ANALYSIS: INTRODUCING TEMPORAL DETERMINATIONS}

Ingarden introduces eight additional existential moments needed to define the way in which a given entity or existential domain is determined (or not) by the passage of time:

1) activeness - non-activeness - post-activeness - empirical possibility (Aktualität - NichtAktualität - Post-Aktualität - Empirische Möglichkeit);

2) fissuration - non-fissuration (Spalthaftigkeit - Nicht-Spalthaftigkeit);

3) permanence ${ }^{24}$ - fragility (Dauerhaftigkeit - Gebrechlichkeit)

An entity is active if it exists in time, and specifically if it presently exists. It is non-active if it exists, as it were, "outside of time", in an eternal realm beyond any kind of temporal determination (such are ideal entities - ideal objects, relations and states of affairs - and purely intentional entities ${ }^{25}$ ). It is post-active if it exits in the past (one might be tempted to say "if it has existed", but this would be slightly confusing since according to Ingarden past existence is a distinctive concept of being, not to be confused with mere non-being). It is empirically possible if it can exist, and indeed if it will: empirical possibility is an existential moment shared by future objects, processes, events and properties. An active entity is fissured if it is "trapped" in the passage of time, the present moment being metaphorically pictured as a fissure through which time flows; it is non-fissured if it does not depend in such a way on the passage of time through the present moment. Finally, an active entity is permanent if it exists "sempiternally", meaning that it enjoys an everlasting existence in time without beginning or end; it is on the contrary fragile if it is perishable and will eventually come to an end.

24 "Dauerhaftigkeit" is often translated by "persistence", but in my opinion this is very misleading since Ingarden frequently refers to real objects as "objects persisting in time" (in der Zeit verbarrenden Gegenstände), and these precisely have the existential moment of Gebrechlichkeit, not Dauerhaftigkeit. In his translation of the Controversy, Arthur Szylewicz prefers to use the word "durability", which is better, but still fails to convey the idea that entities endowed with Dauerhaftigkeit are never-ending. The best philosophical translation of the notion would probably be "sempiternity", which indicates an infinite existence in time (whereas "eternity" might be associated to non-actuality, the idea of an existence outside of time). However, I opted for a simpler translation, "permanence", which is consistent with the ordinary use of 'Dauerhaftigkeit' in German.

${ }^{25}$ Ingarden speaks of "Inaktualität" rather than "Nicht-Aktualität" in the case of purely intentional objects, processes, events and properties, but the basis of this distinction is not obvious: fictional objects such as Hamlet seem to exist outside of time. One might construe the notion of "inactiveness" as implying the idea of a discontinuous existence in time, which would be consistent with the fact that intentional entities are enacted in acts of consciousness. But it would be peculiar to say that the object Hamlet itself comes in and out of existence each time someone thinks about it. Besides, there is also a relation of existential derivation between the text Hamlet and the object Hamlet. 
Based on Ingarden's analysis, these definitions can be clarified and completed by the following existential axioms:

(12) $\forall x \operatorname{Fissured}(x) \vee \operatorname{Non}-$ fissured $(x) \rightarrow \operatorname{Active}(x)$

(13) $\forall x \operatorname{Fragile}(x) \vee \operatorname{Permanent}(x) \rightarrow \operatorname{Active}(x)$

(14) $\forall x \operatorname{Permanent}(x) \rightarrow \operatorname{Autonomous}(x) \wedge \operatorname{Original}(x) \wedge \operatorname{Selfsufficient}(x) \wedge \operatorname{Independent}(x)$

(15) $\forall x$ Fragile $(x) \rightarrow$ Autonomous $(x) \wedge \operatorname{Derivative}(x) \wedge$ Fissured $(x)$

(16) $\forall x \operatorname{Active}(x) \rightarrow \operatorname{Autonomous}(x)$

(17) $\forall x$ Post-active $(x) \rightarrow \operatorname{Autonomous}(x) \wedge \operatorname{Derivative}(x)$

(18) $\forall x$ Empirically Possible $(x) \rightarrow \operatorname{Heteronomous~}(x) \wedge \operatorname{Derivative}(x)$

Therefore, by the axioms (16) and (17), if the real world is temporally determined -i.e. if its constituents are first active, then post-active as time goes by - , it has to exist autonomously; in this case IDC-I and IUC-I, according to which the real world is heteronomous, are ruled out. Similarly, if pure consciousness is temporally determined, it has to exist autonomously, which means that the seventh and eighth groups are disqualified - AR-VII and AR-VIII are ruled out.

In order to draw this conclusion, Ingarden has to make three controversial assumptions. The first two regard the temporal determinations of the real world and pure consciousness respectively: how do we know that their constituents have the existential moments of activeness and post-activeness? The third one concerns the axioms (16) and (17) themselves: why is it that heteronomous entities cannot be active or post-active? Ingarden emphasizes the fact that the interpretation of these three assumptions rests on an ambiguity, which in turn bears on their assessment. This is why he starts by clarifying the axiom (16), in order to specify in what sense activeness and heteronomy are intertwined ${ }^{26}$. He does so by directly addressing a potential objection according to which heteronomous entities, such as purely intentional objects, can be active. One could argue for instance that Hamlet, despite being a heteronomous construct grounded in a literary text, is active: he is human, and as such he is born, he dies, and he lives through time; therefore he seems fragile, fissured and indeed active. However it is easy to see that there is something wrong with this line of reasoning: as Ingarden puts it, entities existing in real time are characterized by "genuine activeness", whereas fictional entities are immersed in a "merely intentionally projected time". This important distinction was introduced in 1931 in the \$36 of Das literarische Kunstwerk (henceforth Kunstwerk) - a work actually conceived as a preliminary study for Controversy. In Kunstwerk, Ingarden explains that the "time" of a literary work of art is nothing more than the order of succession of what takes place in the story. There is no real past, present and future in the heteronomous realm of the works of art, only intentional events taking place in a predefined order. One should be careful not to confuse the temporal aspect of the act of reading, for instance, with a real temporal determination of intentional entities. As Ingarden puts it, in a work of art one finds a "leveling" of all temporal instants through a mere order of succession, because intentional entities do not pass through a phase of genuine in actu esse. Interestingly, this analysis echoes J.M.E. McTaggart's famous distinction between two fundamental ways of describing time, the A-series and the B-series ${ }^{27}$ : the A-series

\footnotetext{
${ }^{26}$ In this whole development, Ingarden ignores the entailment I have formulated as the axiom (17), because it simply follows from (16): temporally determined entities pass through the "activeness-sphere", as he puts it, being successively active then post-active. Therefore, a post-active entity has been active before, and since an autonomous entity cannot become heteronomous, it has to remain autonomous if (16) is true.

${ }^{27}$ J.M.E. McTaggart, 1908, “The Unreality of Time”, Mind, 17, pp. 457-73. Ingarden himself never mentions McTaggart, and is rather influenced by Bergson when he draws this distinction.
} 
resorts to indexical terms such as "past", "present" and "future", which are necessarily relativized to a certain position in time, whereas the B-series only uses a relation of antecedence between times ("earlier than"/"later than"), which is absolute. To paraphrase Ingarden's idea, in McTaggart's lexicon, the time of purely intentional entities is reducible to the B-series, while real time is not, because it can only be described with the A-series. Ingarden generalizes this idea to conclude that there is no past, present and future in the realm of heteronomous entities - only a virtual order of succession. In other words: real time involves real passage, whereas projected time is purely static.

In Controversy, Ingarden goes on to say that this distinction is not satisfactory as it stands, because it was implicitly justified in Kunstwerk by the assumption that the real world is autonomous - since in this previous work he was only concerned with the status of fictional entities. The argument found in Kunstwerk can be abridged in the following way ${ }^{28}$ :

(1) The real world is existentially autonomous.

(2) If the real world is autonomous, its objects pass through real time.

(3) Intentional entities are existentially heteronomous.

(4) If intentional entities are heteronomous, their temporal determination is merely an analogue of the temporal determination of worldly objects.

(5) Therefore, intentional entities do not pass through real time.

Obviously, the premise (1) would beg the question in the existential-ontological analysis of Controversy. Consequently, Ingarden attempts to establish the same distinction between two different kinds of times while avoiding the risk of a vicious circle. He starts by acknowledging the existence of a phenomenal difference between actual time (given in experience) and the intentionally projected time: we directly experience the privileged status of the present moment, which is distinctive of real time. Real time is irreducibly perspectival, which is why it can only be described with the A-series: an event $e$ is present, past or future depending on which time is taken as the referential of this statement (in the Middle Ages, my act of writing this sentence was a future event; but as you are currently reading the sentence on print, it belongs to the past). However, there is no such thing as the experience of temporal presence in the intentionally projected time. While reading Alice in Wonderland, it would not make sense to say that Alice is presently jumping in a rabbit hole - except metaphorically. Therefore, Ingarden believes that he has found a legitimate basis to distinguish in a non-circular way (a) genuine activeness, corresponding to a description of time which requires the A-series, and (b) putative activeness, corresponding to a time which can only be accurately described with the B-series. "Putative activeness" refers to an apparent activeness that is intentionally ascribed to an entity's concept of being: the real source of such an "activeness" is external to the entity - it belongs to the subject of the intentional act ${ }^{29}$. Secondly, he argues that there is a necessary link between (i) genuine activeness and genuine autonomy on the one hand, and (ii) putative activeness and putative autonomy on the other hand:

$$
\forall x \text { Genuinely Active }(x) \rightarrow \text { Genuinely Autonomous }(x) .
$$

$\left(16^{* *}\right) \forall x$ Putatively Active $(x) \rightarrow$ Putatively Autonomous $(x)$.

Putative autonomy, of course, is only heteronomy in disguise: again, Hamlet's "autonomy" as a human being is intentionally ascribed from the outside, and does not belong to the concept of being of the heteronomous object called "Hamlet". Ingarden appears to believe that these

\footnotetext{
28 See Kunstwerk, p. 247 and Controversy, pp. 282-3.

${ }^{29}$ When I say metaphorically that Alice is "presently" jumping in a rabbit hole, what I really mean is that I am presently narrating or reading the part of Alice's story where she is said to jump in the hole. Thus I am merely referring to the order of succession of events in the story, but I associate it, in a rather misleading way, to the real time of my act of reading.
} 
entailments are ultimately grounded in experience: we always experience genuine activeness together with genuine autonomy, because only genuinely autonomous things can really change in time. It is impossible to imagine something that would be genuinely active and yet fail to be genuinely autonomous. Merely intentional constructs are not genuinely situated in time, nor do they really change in time. In that respect, the crux of the Controversy comes down to whether or not the real world shares the mode of being of the "worlds" of works of art.

Ultimately, Ingarden acknowledges that the ontological analysis cannot and should not tell us if the real world, or at least some part of it, is genuinely or putatively active. It can only validate conditional statements such as $\left(16^{*}\right)$ and $\left(16^{* *}\right)$. Accordingly, he claims to have established the following: an entity is genuinely temporal only if it is genuinely active in the present (that is to say if its situation in time can only be completely specified with the A-series); and in turn genuine activeness entails genuine autonomy. But at this stage, the (genuine) temporal determination of the real world is only a hypothesis. What about the temporal determination of pure consciousness? Ingarden does not really elaborate on this point in the first volume of Controversy, not even to ground it in experience: it also remains a hypothesis at this stage. Thus any further dismissal of possible solutions to the Controversy within the boundaries of an existential investigation depends on hypothetical statements. We have only examined two of them so far:

(HypOTHESIS 1) The real world is temporally determined.

(HypOTHESIS 2) Pure consciousness is temporally determined.

If HYPOTHESIS 1 is true, then by the definition of temporal determination as genuine activeness and by $\left(16^{*}\right)$ the real world is really autonomous, ruling out IDC-I and IUC-I. Likewise, if HYPOTHESIS 2 is true, pure consciousness is genuinely autonomous, ruling out AR-VII and ARVIII. But Ingarden also considers two additional hypotheses ${ }^{30}$ :

(HyPOTHESIS 3) The real world is fragile.

(Hypothesis 4) Pure consciousness is fragile.

If HypOTHESIS 3 is true, then by (15) the real world is derivative, ruling out all variants of absolute realism (AR-I, AR-II, AR-III, AR-IV, AR-V, AR-VI, AR-VII, AR-VIII) and DR-II. Likewise, if HYPOTHESIS 4 is true, pure consciousness is derivative; but according to Ingarden this does not straightforwardly rule out any additional solution, because the ones in which pure consciousness is not derived from the real world do not exclude its derivation from a third factor (since no solution directly assumes that pure consciousness is original).

With the third and fourth hypotheses (bearing in mind that they respectively entail the first and the second), no less than 11 solutions are ruled out, leaving only the four variants of realist creationism: AC-I, RDC-I, RUC-I and RUC-V. In the conclusion of the existential analysis, Ingarden is hopeful about the remainder of his investigation: the formal and material analyses of pure consciousness and of the real world should respectively tell us if HYPOTHESIS 2 and НYротHESIs 3 are true, and if so the final metaphysical analysis should determine which one of the four remaining solutions is correct. Unfortunately, there are a number of issues with the result of the existential analysis and the project as a whole.

\section{THE APORIA OF THE CONTROVERSY}

\footnotetext{
${ }^{30}$ Note that these are stronger, because they respectively entail the first and second hypotheses by the axiom (13). This development can be found in the $\$ 33$ of Controversy.
} 
The second stage of the existential investigation is, in a way, disappointing: the introduction of temporal moments is not sufficient by itself to narrow down the number of admissible solutions below 15. It only serves to formulate a few existential axioms that should eventually, together with four hypotheses to be tested by further formal and material analyses, rule out a number of solutions. There are two problems at this stage: first, even if the hypotheses later prove to be true, the remaining solutions include RUC-V - which, as I have shown, should have been ruled out by Ingarden ${ }^{31}$. Admittedly, this can be good news if it brings down the number of definitely admissible solutions to 3 at the end of the ontological investigation. But there is a much bigger issue: over the course of his analysis, Ingarden has often considered weaker versions of the proposed solutions, according to which the real world is not original but merely not derived from pure consciousness. If we allow these weaker versions, HYPOTHESIS 3 is unable to rule out any solution, because the real world can be derived from a third factor. In addition, I have shown that under such a reading DUR-V should be admissible and not ruled out. This means that even if the four hypotheses were true, 11 solutions would still be left. Ingarden is aware of this issue, and addresses it by arguing that the admission of a third factor from which the real world could be derived would contravene to the transcendental nature of his analysis. Indeed, the whole investigation of the Controversy revolves around the relation between pure consciousness and the real world, given that our own phenomenological starting point is found in conscious experience. On the other hand, however, Ingarden allows solutions according to which pure consciousness is not derived from the real world; given HYPOTHESIS 4, this means that pure consciousness is derived from a third factor. Does it also force us to relinquish the transcendental mode of analysis? Ingarden does not think so, otherwise he would rule out such cases. But precisely, AC-I, RDC-I, RUC-I and RUC-V, namely all the solutions that would be left if the four hypotheses were true, involve the assumption that pure consciousness is derived from a third factor! Forbidding this possibility would thus have a disastrous outcome: depending on the result of the formal and material analyses, it could rule out every solution to the Controversy, thereby disqualifying the whole investigation as fallacious.

This is for Ingarden a strong incentive to allow the possibility of pure consciousness being derived from a third factor; but in this case it is not clear why the same possibility should not be allowed for the real world. One reason could be that since the transcendental starting point of ontology is pure consciousness, one could extend the existential analysis by investigating the relation between the latter and the third factor from which it is allegedly derived. This could yield a great number of additional combinations, depending on the existential moments attributed to the third factor. But if pure consciousness is autonomous, by the axiom (10) the third factor cannot be heteronomous. Furthermore, if it is derived, then we risk a regressio ad infinitum - since the third factor creates pure consciousness, it can only be derived from a fourth factor, etc. Therefore it has to be original; by the axioms (1) and (2), this means that it must also be selfsufficient and independent. In other words, the mode of being of the third factor must be absolute. This would still leave a number of options regarding the way in which pure consciousness is related to this third factor: is it selfsufficient and independent with respect to it? Regardless of the combinations that could be obtained from this examination, there is a bigger worry: it is dubious that the putative third factor could be subjected to formal and material analyses at all. Indeed, this domain of being is wholly mysterious: unlike the real world, we have no access to it, and its very existence is speculative. In fact, the postulation of an absolute third factor looks like a very unusual kind of theism.

Thus we stand at a crossroads. Consider the three following options:

a) Neither pure consciousness nor the real world can be derived from a third factor.

b) Pure consciousness can be derived from a third factor while the real world cannot.

${ }^{31}$ He nonetheless rules out both variants of Realist Unity Creationism (RUC-I and RUC-V) in the formal analysis. See Streit, II.2, pp. 373-99. 
c) Both pure consciousness and the real world can be derived from a third factor.

Now assume that Hypotheses 1-4 are true. If we choose the option (a), all 64 combinations are ruled out. Even the Negative Solution is dismissed, because it still assumes that consciousness is original (which contradicts HYPOTHESIS 4). In other words, this option entails the truth of ontological nihilism (a doubly negative solution, as it were). This is absurd ${ }^{32}$ : either one or several of the existential axioms/hypotheses are false, or Ingarden's method is deficient as a whole. If we prefer the option (b), there is an absolute domain of being (God?) which creates consciousness, while the latter creates the world. Only three solutions are admissible: AC-I, RDC-I and RUC-I ${ }^{33}$. Finally, if we favor the option (c), 11 solutions are admissible, but the transcendental mode of analysis is undermined. According to Ingarden, this would require us to give up the transcendental stance altogether and start the whole investigation anew on shaky methodological grounds. None of these three outcomes are very appealing. The first and last options compromise the whole project of Controversy. The second one, chosen by Ingarden ${ }^{34}$, is doubly dubitable: not only does it force us to speculate about an absolute domain of being the sole purpose of which is to ground the existence of pure consciousness, but it also assumes that the postulation of this third factor is innocuous for the transcendental mode of analysis if only pure consciousness is derived from it. Both of these requirements might seem somewhat arbitrary.

There is however a deeper reason for the aporetic nature of Ingarden's project: the metaphysical analysis which was supposed to follow the ontological stage is inherently problematic. Indeed, metaphysics is supposed to single out the actual solution to the Controversy; even if ontology ended up with a single possible solution at the end of the formal and material analyses - which does not seem to be the case - metaphysics would still have to ground it in actual facts. But Ingarden's phenomenological starting point is the immanent sphere of pure consciousness: from there how can one expect to gain insight into actual facts concerning the mode of being of the real world? Ontology is entirely a priori: as I have shown, it implicitly relies on classical formal logic to explore the realm of pure possibilities. Ruling out combinations of existential moments based on the rule of non-contradiction is one thing; discovering the actual mode of being of the world is another. In a way, Ingarden tried to explore a middle path between classical ontology (Aristotelian and medieval "metaphysics") and Husserlian phenomenology characterized by the initial epochè. In the end, however, he was trapped in his transcendental stance, which forbade the way to metaphysics. He seems to realize this himself towards the end of the formal-ontological stage of his investigation:

\footnotetext{
"It seems that exactly the absolutely certain viewpoint of the whole controversy about the existence of the world, by starting from the immanently accessible pure consciousness and by carrying out the analyses in the sphere of immanence, is the reason for the failure which we reach at the end of our inquiry ${ }^{35}$."
}

Despite this avowed "failure", Ingarden refuses to give up the standpoint of the transcendental reduction, which he still considers as a precious achievement for philosophy. He conjectures that the material analysis of pure consciousness will be able to unveil interesting correlations that will ultimately give us some insight into the real nature of the world. As we know, he never

\footnotetext{
32 Ingarden clearly says that the existence of pure consciousness is indubitable, as opposed to the existence of the real world.

${ }^{33}$ On a side note, if the real world can only be derived from pure consciousness, HYPOTHESIS 3 is not even needed to rule out DR-II because the axiom (2) already does. In other words, even if it turns out that the real world is not fragile, only 14 or 10 solutions are admissible on purely existential grounds (depending on whether the real world and pure consciousness are temporally determined).

${ }^{34}$ On the possible derivativeness of pure consciousness, see for instance Controversy, p. 169 and p. 178. On the originality of the real world, see ibid, p. 299.

35 Streit, II.2, p. 395.
} 
performed this material analysis, let alone the metaphysical investigation which was supposed to follow, and the third unachieved volume of Controversy focuses on the philosophy of causation.

What is the final result of Ingarden's examination of the Controversy? At the end of the formal-ontological analysis, which confirms HYPOTHESES 1-4 and rules out Realist Unity Creationism, only two solutions are left standing: AC-I and RDC- $\mathrm{I}^{36}$. Both are variants of realist creationism, meaning that pure consciousness is supposed to create an autonomous world. The only difference between the two is that the second is an instance of creatio continua, where the world existentially depends on pure consciousness at all times. But can we even make sense of the idea that consciousness literally creates an autonomous world? Not really, as Ingarden eventually admits, if we think of buman consciousness, which is also supposed to be derived ${ }^{38}$. Only something like a divine mind could create an autonomous world. However this Cartesian move is forbidden: assuming that "pure consciousness" refers to something else than human consciousness jeopardizes the whole project, and violates the transcendental stance. No matter how we try to interpret the outcome of Ingarden's investigation, it seems to be a failure insofar as it was conceived as an attempt to solve the Controversy for good. This does not mean that there is nothing to save in his analysis, since some of the axioms and hypotheses he uses to rule out certain positions are controversial. For instance, one could criticize his analysis of time (especially his assumptions regarding the irreducibility of the A-series to describe real time), and reject the axiom (16). As a result, AR-VII and AR-VIII would remain promising solutions to the Controversy; not only are they intelligible, but they are also compatible with prominent theories in contemporary philosophy of mind, and consistent with scientific facts. In any case, Ingarden's fine-grained distinctions between several kinds of ontological dependence are very interesting in their own right, and anticipate recent developments in the metaphysics of dependence and grounding ${ }^{39}$. Finally, the central thesis according to which existence is polysemous, and that different combinations of existential moments yield different modes of being, is making a comeback in recent years under the guise of ontological pluralism ${ }^{40}$. As archaic as the idea of a controversy over the existence of the world might seem today, Controversy remains a very impressive philosophical accomplishment full of fascinating insights in formal ontology. I hope to have given a faithful glimpse of this conceptual wealth, which should at least pique the curiosity of both phenomenologists and analytic philosophers.

\footnotetext{
36 Streit, II.2, pp. 373-99.

38 In his initial examination of AC-I, Ingarden writes: "One would therefore have to attribute to pure consciousness a genuinely creative power, which - if, as presupposed, it is a matter of the consciousness that is in fact experienced by us - is surely not seriously done by anyone" (Controversy, p. 175).

${ }^{39}$ Cf. for instance K. Fine, 2012, "Guide to Ground", in F. Correia and B. Schnieder (eds.), 2012, Metaphysical Grounding: Understanding the Structure of Reality, Cambridge, Cambridge University Press, pp. 37-80; and F. Correia, 2005, Existential Dependence and Cognate Notions, Munich, Philosophia Verlag.

${ }^{40} \mathrm{Kr}$. McDaniel, 2009, "Ways of Being", in D. Chalmers, D. Manley and R. Wasserman (eds.), 2009, Metametaphyics, Oxford, Oxford University Press, pp. 290-219; J. Turner, 2010, “Ontological Pluralism”, The Journal of Philosophy 52 (1), pp. 5-34.
} 
Appendix: a synoptic diagram of Ingarden's ontology

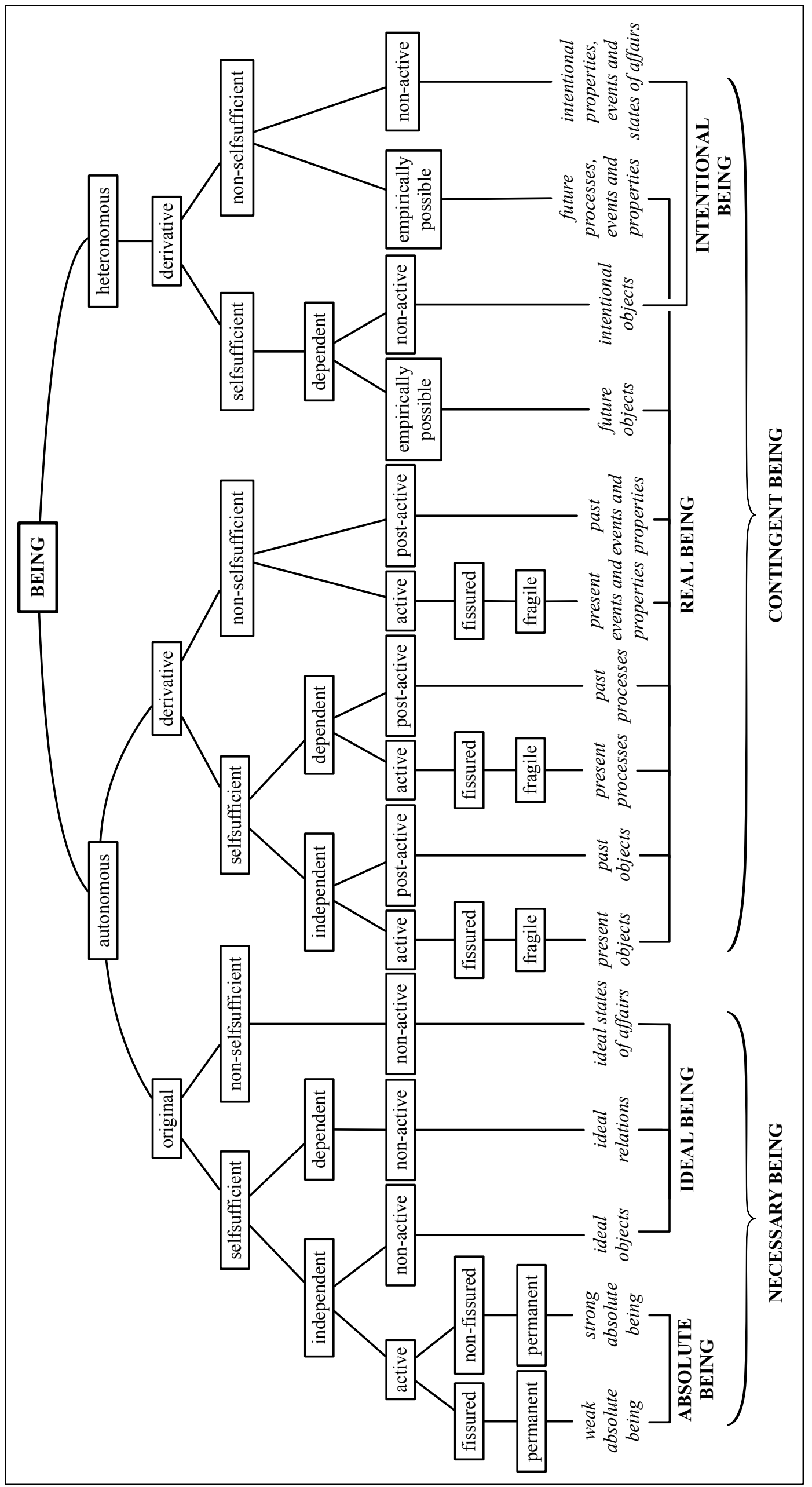

